\title{
Reduction of Molten Iron Oxide in CO Gas Conveyed System*
}

\author{
By Fumitaka TSUKIHASHI,** Kimio KATO,*** Ken-ichi OTSUKA ${ }^{* * * *}$ \\ and Tanekazu SŌMA****
}

\section{Synopsis}

The kinetics of reduction of molten iron oxide with $\mathrm{CO}$ gas at high temperatures of 1450 and $1600^{\circ} \mathrm{C}$ were investigated. In order to reduce the influence of mass transfer rate on overall reaction rate of reduction, fine powders of iron oxide were used as specimen and were reduced in a transport reactor. After the specimens of fine powder of reagent grade were melted during falling down in reaction zone, liquid oxide drops thus formed were reduced with $\mathrm{CO}$ gas. Mean diameter of liquid particles was $25 \mu m$.

The oxide particles were melted and became spherical, and the reduced iron was surrounded by liquid iron oxide. It is assumed that liquid iron oxide always exists on whole spherical surface and the nucleation, growth and cohesion of iron in liquid drop did not infuence the overall reaction. The results were analyzed by considering only the mass transfer in a gas film and the chemical reaction at the gas liquid interface.

The value of mass transfer coefficient in gas film $k_{g}$ was estimated by using the Ranz-Marshall equation

$$
\frac{k_{g} d}{D}=2.0+0.6 R e^{1 / 2} S c^{1 / 3}
$$

Considering the shrinkage of particles by production of metallic iron, the values of rate constant of chemical reaction $k_{c}$ were obtained as $19.4 \mathrm{~cm} /$ sec at $1600^{\circ} \mathrm{C}$ and $9.3 \mathrm{~cm} / \mathrm{sec}$ at $1450^{\circ} \mathrm{C}$.

\section{Introduction}

The reduction reaction of iron oxide in molten state is an elementary and important reaction, since it contributes to understanding the reaction of softening and melting zone in a blast furnace and developing of the smelting processes. The iron oxide in molten state reacts with refractory so fast that the experiment of reduction at high temperature was very difficult and few reports have been provided on this study.

The reduction reaction of molten iron oxide is

$$
\mathrm{FeO}(\mathrm{l})+\mathrm{G}(\mathrm{s})=\mathrm{Fe}(\mathrm{l} \text { or } \mathrm{s})+\mathrm{CO}(\mathrm{g})
$$

or

$$
\mathrm{FeO}(\mathrm{l})+\mathrm{CO}(\mathrm{g})=\mathrm{Fe}(\mathrm{l} \text { or } \mathrm{s})+\mathrm{CO}_{2}(\mathrm{~g})
$$

A few studies of reduction of iron oxide in molten state with solid carbon have been reported. ${ }^{1-5)}$ Few studies on kinetics of reduction reaction of molten iron oxide with $\mathrm{CO}$ gas have been made.

P. Grieveson and E. T. Turkdogan ${ }^{6)}$ have reported the reduction kinetics of molten iron oxide. After equilibrium was established between iron oxide and the mixture of $\mathrm{CO}$ and $\mathrm{CO}_{2}$ gases of specified composition, the molten iron oxide in iridium crucible was oxidized and reduced at $1550{ }^{\circ} \mathrm{C}$. They con- cluded that the rate controlling step is interdiffusion of iron and oxygen.

Some of the authors, Kato, Sasaki and Sōma, ${ }^{7)}$ have reduced the molten iron oxide with $\mathrm{CO}$ gas that was blown downward onto the oxide surface in recrystallized alumina crucible at $1600^{\circ} \mathrm{C}$ and investigated the reduction kinetics of molten iron oxide with CO gas. They reported that the reduction rate is proportional to square root of gas flow rate when the gas flow rate is in the range of 0.6 to $16 \mathrm{Nl} / \mathrm{min}$ and the rate controlling step is mass transfer in gas film and the rate constant of chemical reaction of Eq. (2) is extremely large.

But the chemical reaction rate of reduction of iron oxide in molten state with $\mathrm{CO}$ gas is not clarified. So the purpose of this report is to estimate the rate constant of chemical reaction of molten iron oxide with $\mathrm{CO}$ gas. In order to reduce the influence of mass transfer rate on the overall reaction rate of reduction, fine powders of iron oxide were used as specimen in this experiment. The specimen was transported in dilutely dispersed state and then melted during falling down in reaction zone and liquid oxide drops were reacted with $\mathrm{CO}$ gas. The present report discusses the rate controlling mechanism of reduction reaction of molten iron oxide with $\mathrm{CO}$ gas at high temperatures of 1450 and $1600^{\circ} \mathrm{C}$.

\section{Experimental Method}

\section{Specimen}

The specimen of fine iron oxide powder used in this study was iron oxide powder of reagent grade. To obtain fine particles having a narrow size distribu-

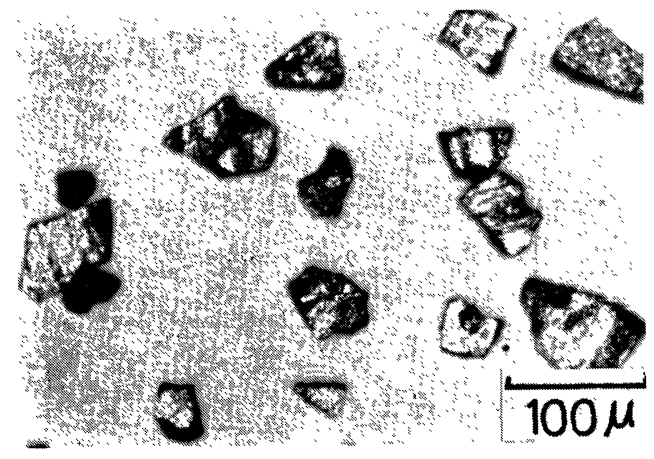

Photo. 1. External view of wustite specimen.

* $\quad$ Originally published in Tetsu-to-Hagané, 68 (1982), 750, in Japanese. English version received July 24, 1981. (C) 1982 ISIJ

** Graduate School, The University of Tokyo, Hongo, Bunkyo-ku, Tokyo 113.

*** Formerly Graduate School, The University of Tokyo. Now at Yawata Works, Nippon Steel Corporation, Yawatahigashi-ku, Kitakyushu 805.

**** Faculty of Engineering, The University of Tokyo, Hongo, Bunkyo-ku, Tokyo 113. 
tion under 325 mesh, iron oxide powders were classified by sedimentation method. Photograph 1 shows the external view of specimen of iron oxide. Their shapes are angular. The X-ray diffraction pattern of the specimens shows that they contained not only wustite but also magnetite. From the chemical analysis the content of T. Fe was 74.0 to $74.2 \%$.

\section{Apparatus and Method}

If the reaction rate of fine liquid drop with reducing gas is measured in dispersed state, the effect of mass transfer rate on overall reaction rate may be small. Accordingly the reduction reaction was proceeded by using transport reactor. So as to reduce oxide drops to various reduction degrees, the residence time of liquid particles in the reaction zone was varied by changing the reducing gas flow rate. After passing through a reaction zone, the liquid particles were quenched in a cooling zone immediately to stop the reduction. Then reacted particles were submitted to the chemical analysis of T.Fe in order to determine the degree of reduction.

The schematic diagram of experimental apparatus is illustrated in Fig. 1. Figure 2 shows the schematic cross section of the chemical reactor and feeder of oxide particles used. Fluidized bed was used to supply the specimen to the stream of CO gas. The dis-

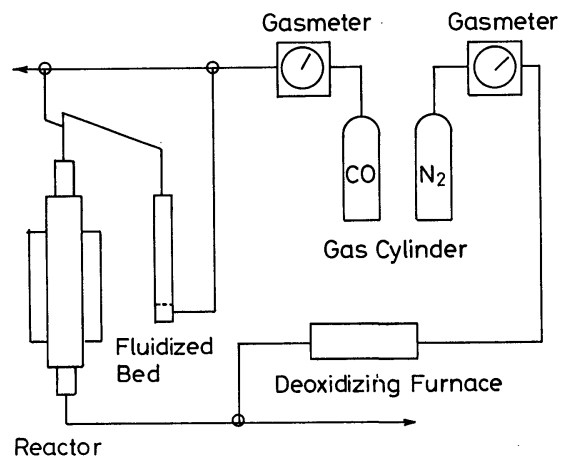

Fig. 1. Schematic diagram of experimental apparatus.

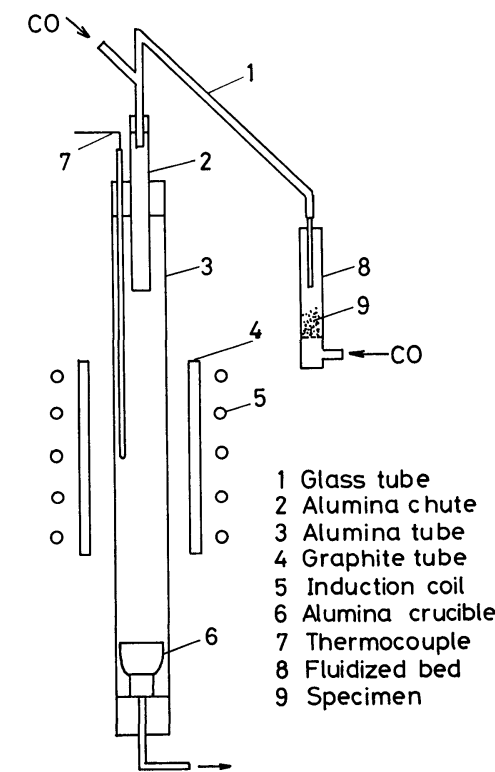

Fig. 2. Schematic cross section of chemical reactor. persed iron oxide particles were introduced into the chemical reactor with gas flow. The reduction was carried out in recrystallized mullite combustion tube (42 $\mathrm{mm}$ i.d., $50 \mathrm{~mm}$ o.d., $600 \mathrm{~mm}$ length) that was indirectly heated by a graphite tube inserted in a high frequency induction coil. An alumina crucible was set at the bottom of the reactor tube in cooling zone to collect the reduced particles of iron oxide.

Experimental temperature was measured by $\mathrm{Pt} 6 \% \mathrm{Rh}-\mathrm{Pt} 30 \% \mathrm{Rh}$ thermocouple located at the center of the reactor tube, and was controlled by manual adjustment. All experiments were carried out at 1450 and $1600^{\circ} \mathrm{C}$. The isothermal zone, which was the region of experimental temperature $\pm 15^{\circ} \mathrm{C}$, was $10 \mathrm{~cm}$ long and this length of isothermal zone was used for calculation of the residence time of iron oxide particles in reaction zone.

Inlet system of $\mathrm{CO}$ gas from reservoir to reactor consisted of two paths, one of which was a pass through the fluidized bed and the other was a short cut pass directly to the reactor. Experiments started when the CO gas was introduced into the fluidized bed and fine iron oxide particles were fluidized. The maximum flow rate of $\mathrm{CO}$ gas to supply the specimen uniformly from fluidized bed to reactor is $1.8 \mathrm{~N} l / \mathrm{min}$. In the case that the $\mathrm{CO}$ gas flow rate was less than $1.8 \mathrm{~N} / / \mathrm{min}$, all of $\mathrm{CO}$ gas passed through the fluidized bed and flowed to the reaction zone, transporting fine iron oxide. In the case that the gas flow rate was more than $1.8 \mathrm{~N} l / \mathrm{min}$, part of gas flowed directly to the reaction zone without passing through fluidized bed and the specimen of fine iron oxide was dispersed uniformly and supplied to reaction zone. After the gas in chemical reactor was replaced with the $\mathrm{CO}$ gas, the fluidization was started and iron oxide powder was carried to the reactor through glass tube. The iron oxide powder was melted and reduced with $\mathrm{CO}$ gas during falling down in reactor tube, then deposited in an alumina crucible set at the bottom of the tube. Each experimental time was 7 to $10 \mathrm{~min}$ and the total amount of oxide particles conveyed with $\mathrm{CO}$ gas was 1.0 to $3.0 \mathrm{~g}$. After the experiment, the reactor was flushed with deoxidized $\mathrm{N}_{2}$ gas to prevent the reoxidization of reduced particles. The reduced iron oxide was analyzed chemically to give the value of total iron percent (T.Fe\%). From the value of

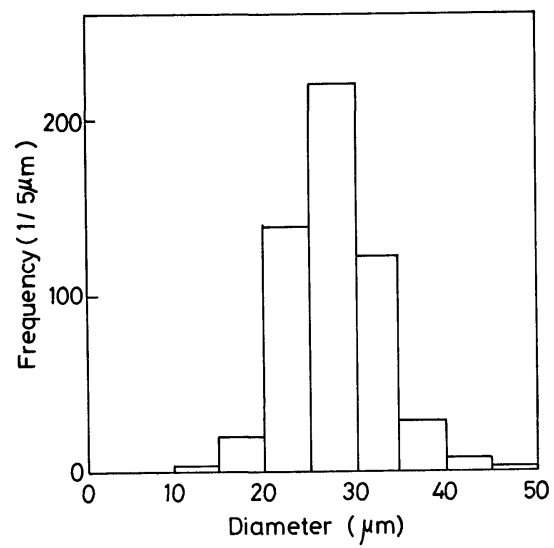

Fig. 3. Typical size distribution of molten wustite particles. 
$\mathrm{T} . \mathrm{Fe} \%$, the degree of reduction $(R \%)$ was calculated by the following equation.

$$
R \%=\frac{100(1-\mathrm{T} \cdot \mathrm{Fe}(1) / \mathrm{T} \cdot \mathrm{Fe}(2))}{100-\mathrm{T} \cdot \mathrm{Fe}(\mathrm{l})} \cdot 100
$$

The mean diameter of oxide particles was determined by taking a microscopic photographs of them and measuring the diameters of 500 to 800 particles melted in $\mathrm{N}_{2}$ gas conveyed system. The mean diameter was $25 \mu \mathrm{m}$. Figure 3 shows the typical distribution of particle diameters. The residence time of particles in the isothermal zone was calculated by the following equation (4):

$$
\begin{aligned}
U_{p} & =U_{g}+U_{s} \\
U_{s} & =\frac{\left(\rho_{p}-\rho_{g}\right) \cdot g \cdot \bar{d}^{2}}{18 \mu} \\
U_{g} & =Q / S \\
t & =L / U_{p}
\end{aligned}
$$

The velocity of particle $U_{p}$ was the sum of the gas velocity $U_{g}$ and the Stokes' terminal velocity $U_{s}$, and the residence time was the time that the particle was required to pass through the isothermal zone of $10 \mathrm{~cm}$ length with velocity $U_{p}$. Viscosity of gas was determined from Eq. $(5)^{8)}$ :

$$
\mu=2.6693 \cdot 10^{-5} \cdot \frac{\sqrt{M T}}{\sigma^{2} \Omega \mu}
$$

\section{Experimental Results}

\section{Experimental Results of Reduction at $1600^{\circ} \mathrm{C}$}

Table 1 shows the results of reduction of molten iron oxide with $\mathrm{CO}$ gas at $1600^{\circ} \mathrm{C}$. In each experiment, the size distribution of specimen after reduction was measured by the microscopic photograph of the specimen. And the value of mean diameter was used to calculate the terminal velocity. So in each exper-

Table 1. Experimental results of reduction of wustite with $\mathrm{CO}$ gas at $1600^{\circ} \mathrm{C}$.

\begin{tabular}{r|rrrrrr}
\hline No. & $\begin{array}{c}Q \\
(\mathrm{~N} l / \mathrm{min})\end{array}$ & $\begin{array}{c}U_{g} \\
\mathrm{~cm} / \mathrm{sec})\end{array}$ & $\begin{array}{c}U_{s} \\
(\mathrm{~cm} / \mathrm{sec})\end{array}$ & $\begin{array}{c}U_{p} \\
(\mathrm{~cm} / \mathrm{sec})\end{array}$ & $\begin{array}{c}t \\
(\mathrm{sec})\end{array}$ & $\begin{array}{c}R \\
(\%)\end{array}$ \\
\hline 1 & 0.91 & 7.51 & 2.15 & 9.66 & 1.035 & 44.2 \\
2 & 1.20 & 9.90 & 2.46 & 12.36 & 0.809 & 43.5 \\
3 & 1.27 & 10.48 & 2.19 & 12.67 & 0.789 & 54.7 \\
4 & 1.02 & 8.42 & 2.40 & 10.82 & 0.924 & 62.3 \\
5 & 1.60 & 13.21 & 2.36 & 15.57 & 0.642 & 52.4 \\
6 & 1.99 & 16.42 & 2.18 & 18.60 & 0.538 & 38.2 \\
7 & 1.62 & 13.37 & 2.54 & 15.91 & 0.629 & 43.7 \\
8 & 0.93 & 7.68 & 2.02 & 9.70 & 1.031 & 60.8 \\
9 & 2.42 & 19.97 & 3.79 & 23.76 & 0.420 & 37.1 \\
10 & 3.10 & 25.59 & 4.51 & 30.10 & 0.332 & 24.7 \\
11 & 0.67 & 5.53 & 2.39 & 7.92 & 1.263 & 71.1 \\
12 & 3.72 & 30.70 & 4.14 & 34.84 & 0.287 & 21.9 \\
13 & 1.78 & 14.69 & 2.11 & 16.80 & 0.595 & 26.0 \\
14 & 2.66 & 21.96 & 2.63 & 24.59 & 0.407 & 23.6 \\
15 & 1.80 & 14.86 & 1.48 & 16.34 & 0.612 & 35.0 \\
16 & 2.40 & 19.81 & 1.79 & 21.60 & 0.463 & 29.2 \\
\hline
\end{tabular}

iment, the terminal velocities were different. The relation between the degree of reduction and the residence time at $1600^{\circ} \mathrm{C}$ is shown in Fig. 4. It becomes clear that the liquid iron oxide was reduced about $60 \%$ during first $1 \mathrm{sec}$. Photograph 2 is the external view of reduced particles and it shows that the oxide particles become melted and spherical. The microstructure of cross section of particles, reduction degrees of which were 23.9 and $60.8 \%$, are shown in Photo. 3. The white round part is the reduced iron and is surrounded by the dark part of wustite. The reduced iron was surrounded by wustite, so the reduction reaction occurred on all surface of wustite particles. From the observation of microstructure of the reduced specimen etched with nital, it is found that the reduced iron was not carburized.

\section{Experimental Results of Reduction at $1450^{\circ} \mathrm{C}$}

Table 2 shows the experimental results at $1450{ }^{\circ} \mathrm{C}$. Figure 5 is the relation between the degree of reduction and the residence time in the reaction zone at $1450{ }^{\circ} \mathrm{C}$. In this case the length of isothermal zone was also $10 \mathrm{~cm}$ and the mean diameter of particles reduced at $14500^{\circ} \mathrm{C}$ was the same as that at $1600^{\circ} \mathrm{C}$. From the comparison of Figs. 4 and 5, it is found that the reduction rate at $1450^{\circ} \mathrm{C}$ is smaller than that at $1600^{\circ} \mathrm{C}$. Photograph 4 shows the microstructure of cross section of reduced particles at $1450{ }^{\circ} \mathrm{C}$. The degrees of reduction were 26.1 and $35.1 \%$. In most experiments, several iron particles were dispersed inside a wustite particle as shown in Photo. 4. As a result of etching of reduced specimens with nital, the carburization of spherical iron also was not observed. At this experimental temperature of $1450^{\circ} \mathrm{C}$, wustite

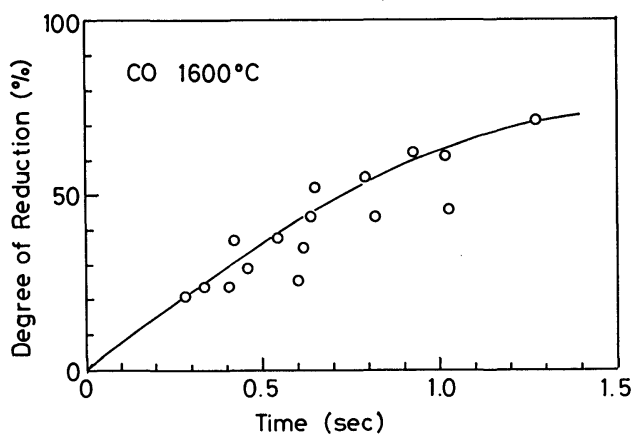

Fig. 4. Time change of reduction degree of wustite at $1600{ }^{\circ} \mathrm{G}$.

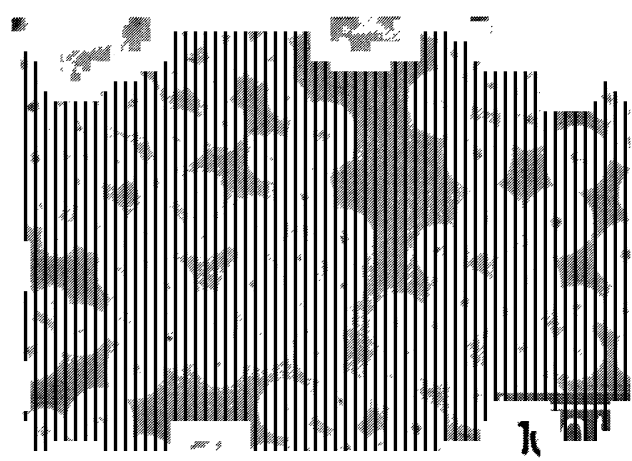

Photo. 2. External view of reduced wustite particles at $1600^{\circ} \mathrm{C}$. 


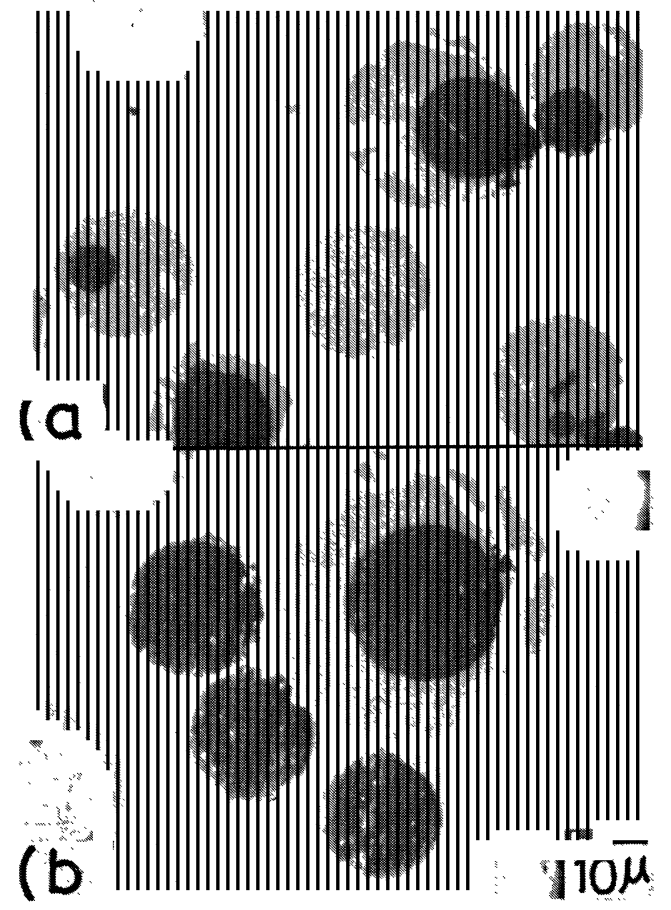

Reduction degree: (a) $23.9 \%$ (b) $60.8 \%$

Photo. 3. Cross section of reduced wustite particles at $1600^{\circ} \mathrm{G}$.

Table 2. Experimental results of reduction of wustite with $\mathrm{CO}$ gas at $1450^{\circ} \mathrm{C}$.

\begin{tabular}{r|rrrrrr}
\hline No. & $\begin{array}{c}Q \\
(\mathrm{~N} l / \mathrm{min})\end{array}$ & $\begin{array}{c}U_{g} \\
(\mathrm{~cm} / \mathrm{sec})\end{array}$ & $\begin{array}{c}U_{s} \\
(\mathrm{~cm} / \mathrm{sec})\end{array}$ & $\begin{array}{c}U_{p} \\
(\mathrm{~cm} / \mathrm{sec})\end{array}$ & $\begin{array}{c}t \\
(\mathrm{sec})\end{array}$ & $\begin{array}{c}R \\
(\%)\end{array}$ \\
\hline 1 & 1.04 & 7.90 & 5.77 & 13.67 & 0.732 & 26.6 \\
2 & 1.95 & 14.80 & 2.10 & 16.90 & 0.591 & 35.1 \\
3 & 2.35 & 17.84 & 2.81 & 20.65 & 0.484 & 28.3 \\
4 & 0.96 & 7.29 & 1.85 & 9.14 & 1.094 & 40.3 \\
5 & 3.15 & 23.91 & 1.98 & 25.89 & 0.386 & 27.0 \\
6 & 1.44 & 10.93 & 2.42 & 13.35 & 0.749 & 29.9 \\
7 & 3.29 & 24.98 & 1.70 & 26.68 & 0.375 & 35.0 \\
8 & 1.38 & 10.48 & 2.87 & 13.35 & 0.749 & 34.3 \\
9 & 0.74 & 5.62 & 2.05 & 7.67 & 1.304 & 62.4 \\
10 & 2.36 & 17.92 & 3.12 & 20.94 & 0.478 & 26.1 \\
\hline
\end{tabular}

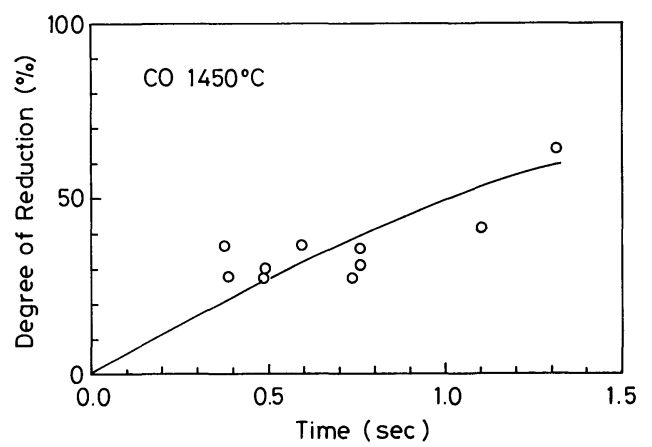

Fig. 5. Time change of reduction degree of wustite at $1450^{\circ} \mathrm{C}$.

was in molten state but reduced iron did not melt. So in this case, at the temperature of $1450^{\circ} \mathrm{C}$, the wustite in molten state surrounded the reduced iron, and wustite reacted with $\mathrm{CO}$ gas on all surface of spherical wustite.

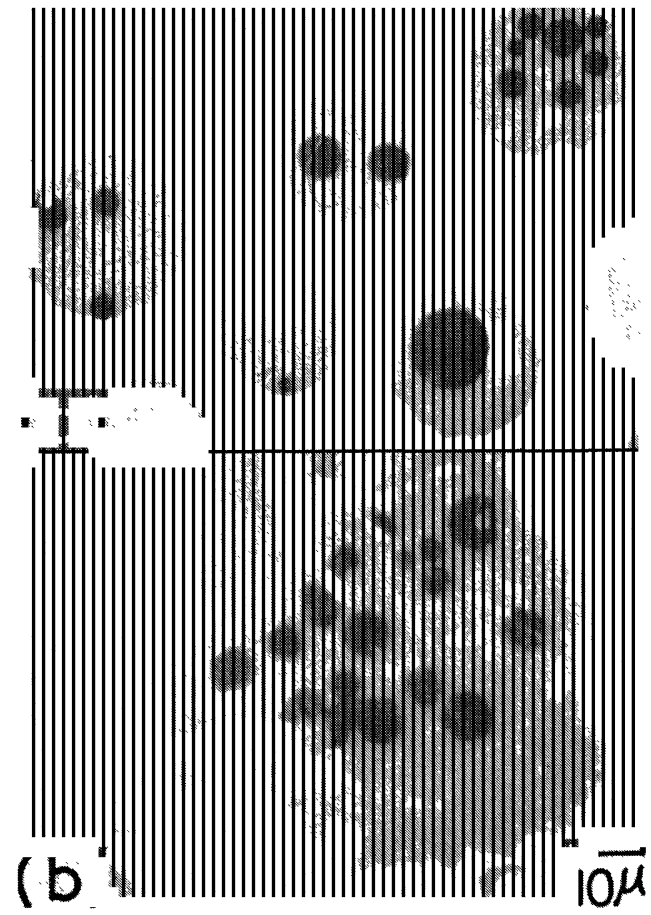

Reduction degree: (a) $26.1 \%$ (b) $35.1 \%$

Photo. 4. Cross section of reduced wustite particles at $1450{ }^{\circ} \mathrm{C}$.

\section{Effect of Particle Diameter on Reduction Rate}

To estimate the effect of diameter on reduction rate, smaller specimens were made by crushing and sieving in water. The mean diameter of them was $16 \mu \mathrm{m}$. Figure 6 shows the effect of particle diameter on the reduction rate at $1600^{\circ} \mathrm{C}$. When the diameter became smaller, the reduction rate was smaller.

\section{Effect of Prereduction Degree on Reduction Rate}

It is known that $\mathrm{Fe}^{3+} / \mathrm{Fe}^{2+}$ ratio influences the interdiffusion coefficient. Then, if the diffusion in liquid drop is a factor controlling the reaction rate, the $\mathrm{Fe}^{3+} / \mathrm{Fe}^{2+}$ ratio will be found to affect the reaction rate. So the prereduced specimen of fine iron oxide was reduced in transport reactor. Figure 7 shows the relation between the degree of reduction of prereduced iron oxide in molten state and the time. The ratio of $\mathrm{Fe}^{3+} / \mathrm{Fe}^{2+}$ hardly influenced the reduction rate.

\section{Discussion}

According to the observation of cross section of reduced particles, the reduced spherical iron (solid or liquid) is wrapped with wustite. It is considered that liquid wustite always exists at the gas liquid interface, and the nucleation of iron proceeded on the whole surface of liquid drop. It means that diffusion inside the liquid drop need not be considered. It is supposed that the nucleation, growth and cohesion of iron in liquid drop did not influence the overall reaction rate, and the reduction reaction was analyzed by considering only the mass transfer in gas film and the chemical reaction at the gas liquid interface. Besides, 
the amount of $\mathrm{CO}_{2}$ gas generated with reduction was little and the bulk concentration of $\mathrm{CO}$ gas hardly varied with the progress of the reduction, because only a very few fine iron oxides were conveyed in transport reactor. The reduction reaction was presented by Eq. (2),

$$
\mathrm{FeO}(\mathrm{l})+\mathrm{CO}(\mathrm{g})=\mathrm{Fe}(\mathrm{l} \text { or } \mathrm{s})+\mathrm{CO}_{2}(\mathrm{~g})
$$

The rate of mass transfer in gas film from bulk gas to gas liquid interface $\dot{n}_{g}$ is given by

$$
\dot{n}_{g}=4 \pi r_{p}^{2} k_{g}\left(C_{\mathrm{CO}}^{b}-C_{\mathrm{Co}}^{i}\right)
$$

The rate of chemical reaction at the gas liquid interface $\dot{n}_{c}$ is given by

$$
\dot{n}_{c}=4 \pi r_{p}^{2} k_{c}\left(C_{\mathrm{CO}}^{i}-C_{\mathrm{CO}}^{*}\right) \cdot a_{\mathrm{FeO}}
$$

As assumed that the reaction is steady, hence

$$
\dot{n}_{g}=\dot{n}_{c}=\dot{n}_{\text {overall }}
$$

From Eqs. (6) to (8), as the activity of $\mathrm{FeO}, a_{\mathrm{FeO}}$, is unity, the overall reaction rate $\dot{n}_{\text {overall }}$ is given by

$$
\dot{n}_{\text {overall }}=4 \pi r_{p}^{2} \frac{C_{\mathrm{co}}^{b}-C_{\mathrm{co}}^{*}}{\frac{1}{k_{g}}+\frac{1}{k_{c}}}
$$

Here, as the iron, the density of which is $\rho_{2}$, is produced from the wustite, having the density of $\rho_{1}$, considering the shrinkage of particles by production of metallic iron, the radius of particles is presented as

$$
r_{p}=\sqrt[3]{(1-R)+\frac{\rho_{1}}{\rho_{2}} R} \cdot r_{0}
$$

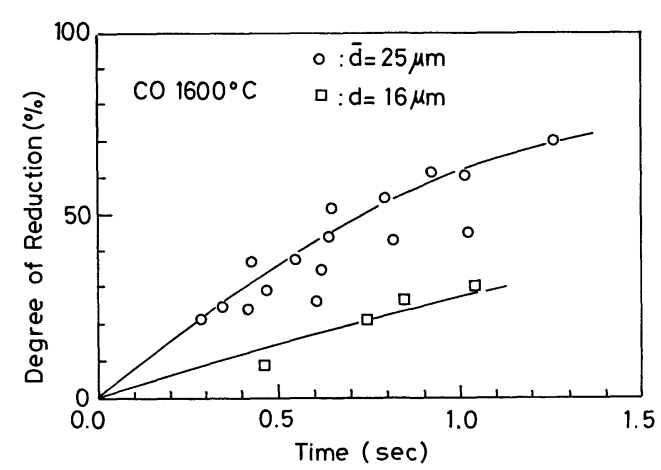

Fig. 6. Effect of wustite particle diameter on reduction rate at $1600^{\circ} \mathrm{C}$.

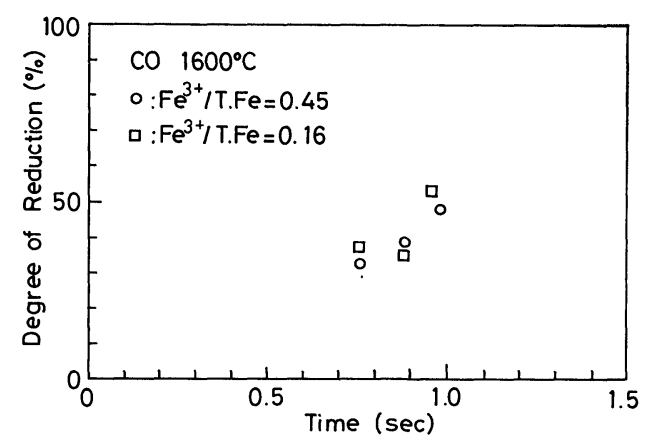

Fig. 7. Effect of prereduction degree on reduction rate at $1600^{\circ} \mathrm{G}$.
Substituting Eq. (10) into Eq. (9), then

$$
\dot{n}_{\text {overall }}=4 \pi\left[1-\left(1-\frac{\rho_{1}}{\rho_{2}}\right) R\right]^{2 / 3} r_{0}^{2} \frac{C_{\mathrm{CO}}^{b}-C_{\mathrm{co}}^{*}}{\frac{1}{k_{g}}+\frac{1}{k_{c}}} \ldots
$$

Equation (11) is rewritten using the relation

$$
\begin{aligned}
& \dot{n}_{\text {overall }}=\mathrm{O}_{i} \frac{d R}{d t} \\
& \mathrm{O}_{i}=\frac{4}{3} \pi r_{0}^{3} \rho_{1} \ldots .
\end{aligned}
$$

thus

$$
\mathrm{O}_{i} \frac{d R}{d t}=4 \pi\left[1-\left(1-\frac{\rho_{1}}{\rho_{2}}\right) R\right]^{2 / 3} r_{0}^{2} \frac{C_{\mathrm{co}}^{b}-C_{\mathrm{CO}}^{*}}{\frac{1}{k_{g}}+\frac{1}{k_{c}}}
$$

By integrating Eq. (14) from 0 to $t$, then

$$
r_{0} \frac{\rho_{1} \rho_{2}}{\rho_{1}-\rho_{2}}\left[1-\left\{1-\left(1-\frac{\rho_{1}}{\rho_{2}}\right) R\right\}^{1 / 3}\right]=\frac{C_{\mathrm{CO}}^{b}-C_{\mathrm{Co}}^{*}}{\frac{1}{k_{g}}+\frac{1}{k_{c}}} t
$$

The densities of iron at 1450 and $1600{ }^{\circ} \mathrm{C}$ are 7.12 and $7.00 \mathrm{~g} / \mathrm{cm}^{3}$, respectively. ${ }^{9)}$ The density of wustite at the temperature of $1450{ }^{\circ} \mathrm{C}$ is $4.35 \mathrm{~g} / \mathrm{cm}^{3}{ }^{10}$ ) It seems to be quite all right to consider that the density of wustite at $1600^{\circ} \mathrm{C}$ is not so different from that at $1450^{\circ} \mathrm{C}$, and that the value of density at $1600^{\circ} \mathrm{C}$ is assumed to be the same as that of $1450^{\circ} \mathrm{C}$. The densities of wustite and molten iron at $1600^{\circ} \mathrm{C}$ represented in the unit of $\mathrm{mol} / \mathrm{cm}^{3}$ are $4.35 / 71.8$ and $7.00 /$ $55.8 \mathrm{~mol} / \mathrm{cm}^{3}$, respectively.

Substituting these values at $1600^{\circ} \mathrm{C}$ into Eq. (15), the relation between $1-(1-0.517 R)^{1 / 3}$ and $t$ is derived. Figure 8 shows this relation of observed data. As the gradient of the line in Fig. 8 represents the value of

$$
\frac{\rho_{1}-\rho_{2}}{r_{0} \rho_{1} \rho_{2}} \cdot\left(C_{\mathrm{CO}}^{b}-C_{\mathrm{Co}}^{*}\right) /\left(1 / k_{g}+1 / k_{c}\right)
$$

the overall resistance $1 / K$ was obtained from the gradient of this line. Equilibrium pressures of $\mathrm{CO}$ gas of the reaction (2) at 1450 and $1600^{\circ} \mathrm{C}$ are calcu-

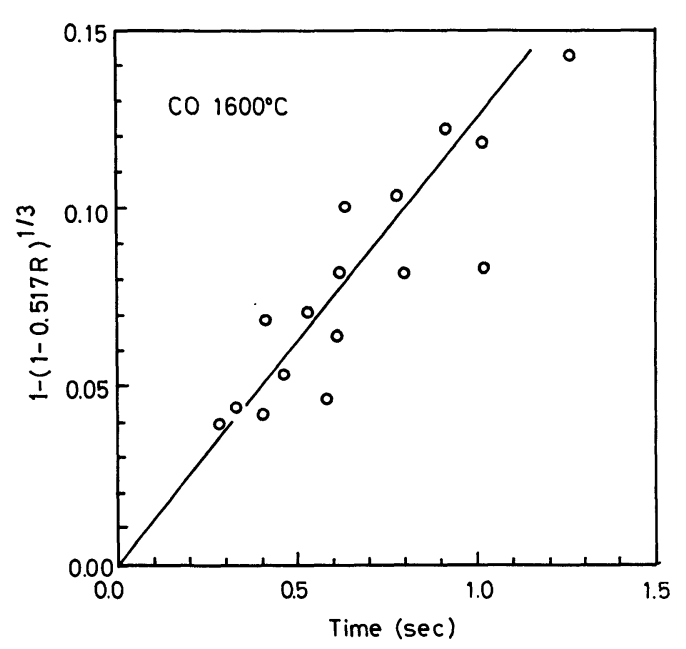

Fig. 8. Relation between time and $1-(1-0.517 R)^{1 / 3}$. 
lated from the following free energy data ${ }^{11)}$ :

$$
\begin{aligned}
& \langle\mathrm{C}\rangle+\frac{1}{2}\left(\mathrm{O}_{2}\right)=(\mathrm{CO}) \\
& \Delta G^{\circ}=-26700-20.95 \mathrm{~T} \quad(298 \sim 2000 \mathrm{~K}) \\
& \langle\mathrm{C}\rangle+\left(\mathrm{O}_{2}\right)=\left(\mathrm{CO}_{2}\right) \\
& \Delta G^{\circ}=-94200-0.20 T \quad(298 \sim 2000 \mathrm{~K}) \\
& \{\mathrm{FeO}\}=\langle\mathrm{Fe}\rangle+\frac{1}{2}\left(\mathrm{O}_{2}\right) \\
& \Delta G^{\circ}=51975-8.855 T \quad(1642 \sim 1808 \mathrm{~K}) \\
& \{\mathrm{FeO}\}=\{\mathrm{Fe}\}+\frac{1}{2}\left(\mathrm{O}_{2}\right) \\
& \Delta G^{\circ}=55620-10.83 \mathrm{~T} \quad(1808 \sim 2000 \mathrm{~K})
\end{aligned}
$$

Since equilibrium pressure of $\mathrm{CO}$ of the reaction (2) is $0.858 \mathrm{~atm}$ when the total pressure is $1 \mathrm{~atm}$, the reduction potential is $0.142 \mathrm{~atm}$ at $1600^{\circ} \mathrm{C}$. This value is translated to the concentration of $\mathrm{CO}$ gas in the unit of $\mathrm{mol} / \mathrm{cm}^{3}$ by using the equation of state of ideal gas. $C_{\mathrm{co}}^{b}-C_{\mathrm{co}}^{*}$ is $9.23 \times 10^{-7} \mathrm{~mol} / \mathrm{cm}^{3}$ at $1600^{\circ} \mathrm{C}$, then from the gradient of the line in Fig. 8, the value

$$
\left[1-\left\{1-\left(1-\frac{\rho_{1}}{\rho_{2}}\right) R\right\}^{1 / 3}\right] / t
$$

is 0.123. Substituting these values into Eq. (15), the value of overall resistance is

$$
\frac{1}{K}=\frac{1}{k_{g}}+\frac{1}{k_{c}}=5.2 \times 10^{-2} \mathrm{sec} / \mathrm{cm}
$$

The value of the mass transfer coefficient in gas film, $k_{g}$, can be estimated by Ranz-Marshall equation $(17) \cdot{ }^{12)}$

$$
\frac{k_{g} d}{D}=2.0+0.6 R e^{1 / 2} S c^{1 / 3}
$$

The value of viscosity of $\mathrm{CO}$ gas, $\mu_{\mathrm{CO}}$, is calculated from Eq. (5) and the value of diffusivity of $\mathrm{CO}-\mathrm{CO}_{2}$ is calculated from Eq. (18).

$$
D_{\mathrm{CO}-\mathrm{CO}_{2}}=0.0018583 \cdot \frac{\sqrt{T^{3}\left(\frac{1}{M_{\mathrm{CO}}}+\frac{1}{M_{\mathrm{CO}_{2}}}\right)}}{P \cdot \sigma^{2} \Omega_{\mathrm{DCO}_{-} \mathrm{CO}_{2}}} \ldots
$$

At $1600{ }^{\circ} \mathrm{C}$, the value of diffusivity, $D$, is $3.6 \mathrm{~cm}^{2} / \mathrm{sec}$ and viscosity is $6.2 \times 10^{-4} \mathrm{~g} / \mathrm{cm} \cdot \mathrm{sec}$, then the calculated value of mass transfer coefficient $k_{g}$ from Eq. (17) is a very large value of $2900 \mathrm{~cm} / \mathrm{sec}$. Substituting these values into Eq. (16), the value of chemical reaction rate constant, $k_{c}$, is $19.4 \mathrm{~cm} / \mathrm{sec}$.

In the same manner as the case of $1600^{\circ} \mathrm{C}$, Fig. 9 shows the relation between

$$
1-\left[1-\left(1-\frac{\rho_{1}}{\rho_{2}}\right) R\right]^{1 / 3}
$$

and $t$ at $1450^{\circ} \mathrm{C}$. From the value of gradient of the line in Fig. 9, the value of

$$
\left[1-\left\{1-\left(1-\frac{\rho_{1}}{\rho_{2}}\right) R\right\}^{1 / 3}\right] / t
$$

is 0.086 . At $1450^{\circ} \mathrm{C}$, interdiffusivity of $\mathrm{CO}-\mathrm{CO}_{2}$,

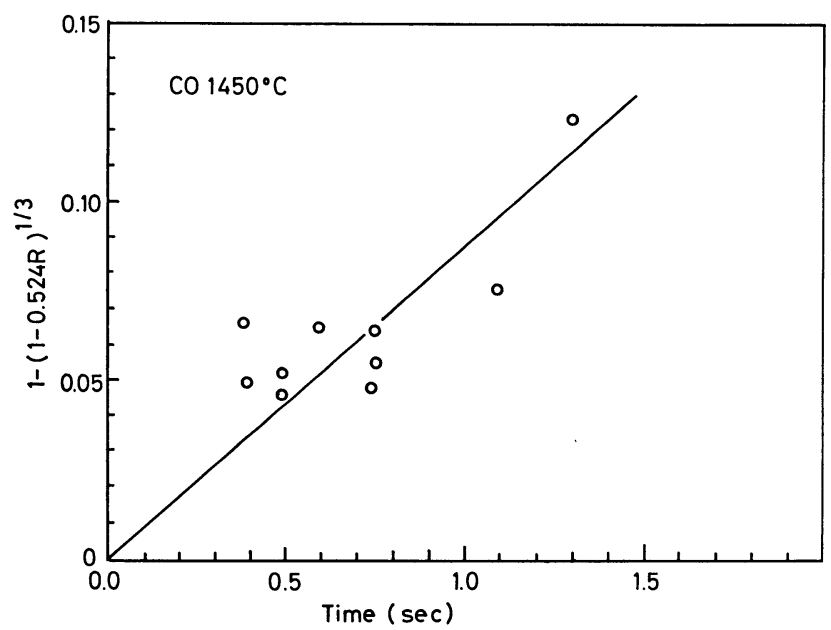

Fig. 9. Relation between time and $1-(1-0.524 R)^{1 / 3}$.

$D_{\mathrm{Co}_{-} \mathrm{CO}_{2}}$, is $3.10 \mathrm{~cm}^{2} / \mathrm{sec}$, the viscosity of $\mathrm{CO}$ gas is $5.9 \times 10^{-4} \mathrm{~g} / \mathrm{cm} \cdot \mathrm{sec}$ and the density of $\mathrm{CO}$ gas is $1.98 \times 10^{-4} \mathrm{~g} / \mathrm{cm}^{3}$. Since the equilibrium pressure of $\mathrm{CO}$ at $1450{ }^{\circ} \mathrm{C}$ is $0.810 \mathrm{~atm}$ when the total pressure is $1 \mathrm{~atm}$, the reduction potential of $\mathrm{CO}$ gas is $0.190 \mathrm{~atm}$. This value corresponds to $C_{\mathrm{co}}^{b}-C_{\mathrm{co}}^{*}=$ $1.34 \times 10^{-6} \mathrm{~mol} / \mathrm{cm}^{3}$ in the unit of $\mathrm{mol} / \mathrm{cm}^{3}$ using the equation of state of ideal gas. Substituting these values into Eq. (15), the overall resistance was obtained.

$$
\frac{1}{k_{g}}+\frac{1}{k_{c}}=\frac{1}{K}=1.08 \times 10^{-1} \mathrm{sec} / \mathrm{cm}
$$

The value of rate constant of chemical reaction $k_{c}$ at $1450^{\circ} \mathrm{C}$ is calculated as $9.3 \mathrm{~cm} / \mathrm{sec}$.

The value of activation energy of chemical reaction calculated from the data of the temperatures of 1450 and $1600{ }^{\circ} \mathrm{C}$ is $31.4 \mathrm{kcal} / \mathrm{mol}$.

As described in the introduction, in the experiment of reduction of molten iron oxide with $\mathrm{CO}$ gas blowing system, the molten iron oxide in alumina crucible was reduced with $\mathrm{CO}$ gas blown onto the surface of molten iron oxide. The $\mathrm{CO}$ gas was blown from the alumina tube of $5 \mathrm{~mm}$ inner diameter set $10 \mathrm{~mm}$ above the molten surface. The flow rate of $\mathrm{CO}$ gas was changed from 0.6 to $16 \mathrm{~N} l / \mathrm{min}$ and because the reaction rate is proportional to the square root of flow rate of $\mathrm{CO}$ gas, it is considered that the rate controlling step is the mass transfer in gas film in the reduction of molten iron oxide with $\mathrm{CO}$ gas blowing system. From the fact that the rate controlling step is the mass transfer in gas film, the chemical reaction rate was estimated indirectly and the estimated value was a very large value that was greater than $1300 \mathrm{~cm} / \mathrm{sec}$.

In this experiment, as the fine oxide specimen was reduced in transport reactor, the mass transfer coefficient in gas film, $k_{g}$, was estimated from the RanzMarshall equation. Usually the Ranz-Marshall equation is applied to estimate the mass transfer coefficient in gas film for pellet the diameter of which is relatively large. But Ranz and Marshall proposed this equation based on the experiment of vaporization of liquid drop the diameter of which is about $1 \mathrm{~mm}$, and 
in any other experiments, this equation was applied to the case of smaller particle. ${ }^{13)}$ So it is reasonable to apply this equation to our specimen of experiment. Because the mass transfer coefficient in gas film, $k_{g}$, estimated from the Ranz-Marshall equation was a very large value in this experiment, it is considered that the resistance of gas film was negligible in this experiment. Consequently the chemical reaction rate constant, $k_{c}$, at $1600^{\circ} \mathrm{C}$ is $19.4 \mathrm{~cm} / \mathrm{sec}$ and the value of $1300 \mathrm{~cm} / \mathrm{sec}$ obtained from the gas blowing experiment could not be verified.

Overall reaction rate in this experiment is $2.8 \times$ $10^{-4} \mathrm{~g}$-Oxygen $/ \mathrm{cm}^{2} \mathrm{sec}$ and that value in gas blowing experiment is 1.6 to $5.0 \times 10^{-4} \mathrm{~g}$-Oxygen $/ \mathrm{cm}^{2} \mathrm{sec}$, both of these values are of the same order.

According to the Ranz-Marshall equation (17), when the diameter of particle is small, the value of mass transfer coefficient in gas film, $k_{g}$, becomes large, and the resistance in gas film which controlled the reaction rate in gas blowing system may be ignored. So the overall reaction rate was expected to increase. But the value of overall reaction rate of this investigation is nearly the same as that of gas blowing system.

Therefore it is necessary to reestimate the reaction rate constant measured by the gas blowing system. In the gas blowing system, the reaction rate was analyzed assuming that the blowing $\mathrm{CO}$ gas exists over the whole reaction surface of molten iron oxide. But in the case that much $\mathrm{CO}_{2}$ gas is generated with the reduction, the reduction potential of reducing gas becomes small. Partial pressure of $\mathrm{CO}$ gas after reaction caused by the generation of $\mathrm{CO}_{2}$ is 0.90 to $0.97 \mathrm{~atm}$, while the pressure before reduction is $1 \mathrm{~atm}$. As the equilibrium pressure of the reaction (2) is $0.86 \mathrm{~atm}$, the decrease of reduction potential caused by the generation of $\mathrm{CO}_{2}$ gas could not be ignored.

Figure 10 shows the overall reaction rate divided by the driving force of reduction plotted against the flow rate of $\mathrm{CO}$ gas. As the flow rate increased, the value of overall reaction rate divided by the mean reduction potential of inlet and outlet increased. If the chemical reaction is the rate controlling step and the chemical reaction rate is proportional to the reduction potential, the value of overall reaction rate

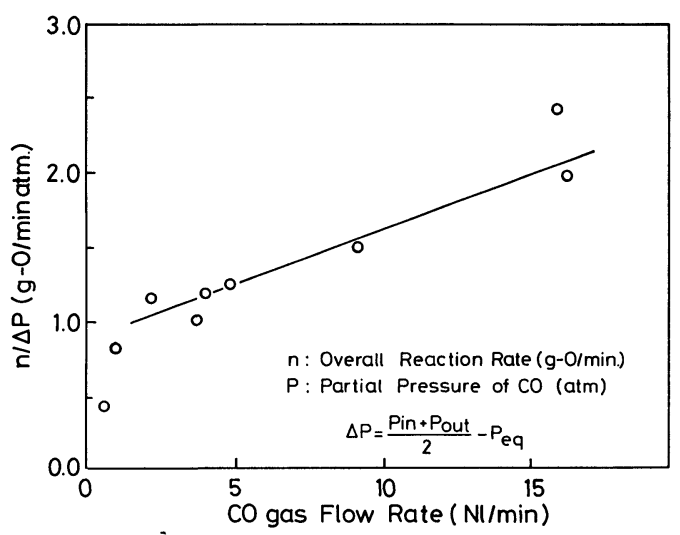

Fig. 10. Overall reaction rate divided by the driving force of reduction plotted against the flow rate of $\mathrm{CO}$ gas. divided by the mean reduction portential of inlet and outlet remains constant. From the fact that this value changes when the $\mathrm{CO}$ gas flow rate increases and the reduction potential becomes nearly constant, the flow rate affects the value of mass transfer coefficient in gas film, $k_{g}$. It is considered that the mass transfer in gas film contributes to the overall reaction rate when the $\mathrm{CO}$ gas flow rate is up to $16 \mathrm{~N} l / \mathrm{min}$.

Taniguchi et al., who investigated the mass transfer in gas blowing system, proposed the following experimental equation based on the experiment of oxidation of graphite in a crucible type of reactor. ${ }^{14)}$

$$
\begin{aligned}
& \frac{k_{g} d}{D}=n\left(\frac{r_{s}}{d}\right)^{-1.5} R e^{0.66} S c^{0.5} \\
& n=0.32 \pm 0.06
\end{aligned}
$$

where, $d$ is the inner diameter of blowing nozzle and $r_{s}$ is the radius of crucible.

As the experiment of Taniguchi et al. ${ }^{14)}$ is similar to the $\mathrm{CO}$ gas blowing system, the experimental results of $\mathrm{CO}$ gas blowing system were analyzed with Eq. (20). Substituting each value of physical properties into Eq. (20), the value of mass transfer coefficient in gas film, $k_{g}$, is about $50 \mathrm{~cm} / \mathrm{sec}$ when the flow rate of $\mathrm{CO}$ gas is $16 \mathrm{~N} l / \mathrm{min}$. This value of mass transfer coefficient in gas film, $k_{g}$, is same as the value of overall reaction rate constant in the case of $16 \mathrm{~N} l / \mathrm{min}$ of gas blowing system, and the mass transfer in gas film is the rate controlling in the $\mathrm{CO}$ gas blowing system.

Because the reaction rate in this experiment decreased when the particle diameter decreased, the dispersion of particles in the reactor becomes important. It is considered that the particle diameter did not increase by cohesion from the measurement of diameter of particles after reduction. If the diameter was small, the particle did not disperse in the reactor and the $\mathrm{CO}_{2}$ concentration becomes greater, but the dispersion phenomenon in transport reactor is not clear.

As shown in Photo. 3 of the cross section of reduced particles, the reduced iron particles were surrounded by the iron oxide particles. At the surface of molten iron oxide, the reduced iron particles were surrounded by iron oxide as soon as the iron particles were generated on the iron oxide-CO gas interface and iron oxide always exists at the surface of iron oxide. As the iron nuclei generated on the surface were surrounded by iron oxide in molten state reduction, it is considered that the rate of nucleation of iron on the iron oxide surface affected the reaction rate.

In the experiment of reduction of molten iron oxide with $\mathrm{CO}$ gas in transport reactor, the chemical reaction constant of reduction of molten iron oxide drop is about $20 \mathrm{~cm} / \mathrm{sec}$, and it is considered that the rate constant of chemical reaction of $\mathrm{CO}$ gas blowing system is much greater than the value of rate constant obtained in transporting system.

\section{Conclusion}

To investigate the reaction mechanism and to estimate the chemical reaction rate of reduction of iron oxide in molten state with $\mathrm{CO}$ gas, fine molten iron 
oxide was reduced in a transport reactor in which the effect of mass transfer in gas film was neglected at the temperatures of 1450 and $1600{ }^{\circ} \mathrm{C}$. Following results were obtained:

(1) Reduction rates of molten iron oxide particles (mean diameter $25 \mu \mathrm{m}$ ) in $\mathrm{CO}$ gas conveyed system were $2.8 \times 10^{-4} \mathrm{~g}$-Oxygen $/ \mathrm{cm}^{2} \mathrm{sec}$ at $1600^{\circ} \mathrm{C}$ and $2.0 \times 10^{-4} \mathrm{~g}-\mathrm{Oxygen} / \mathrm{cm}^{2} \mathrm{sec}$ at $1450^{\circ} \mathrm{C}$. The rate constants of chemical reaction were $19.4 \mathrm{~cm} / \mathrm{sec}$ at $1600{ }^{\circ} \mathrm{C}$ and $9.3 \mathrm{~cm} / \mathrm{sec}$ at $1450{ }^{\circ} \mathrm{C}$. The value of activation energy of chemical reaction calculated from these values is $31.4 \mathrm{kcal} / \mathrm{mol}$. The rate constant of chemical reaction of reduction of molten iron oxide reduced in a transport reactor is less than the value estimated from the result of experiment of $\mathrm{CO}$ gas blowing system.

(2) As the particle diameter becomes smaller from 25 to $16 \mu \mathrm{m}$, rate of reduction becomes lower and slight prereduction of the specimen did not affect the reaction rate.

(3) New phases generated from molten iron oxide were dispersed inside the oxide drop and cohesion of them gave a larger sphere at higher step of reduction. Molten iron oxide surrounded the reduced spherical iron, and the shape of particle is spherical.

\section{Nomenclature}

$a_{\mathrm{FeO}}:$ Activity of wustite (-)

$C_{\mathrm{co}}^{b}$ : Concentration of bulk $\mathrm{CO}$ gas $\left(\mathrm{mol} / \mathrm{cm}^{3}\right)$

$C_{\mathrm{Co}}^{i}$ : Concentration of $\mathrm{CO}$ gas at gas liquid interface $\left(\mathrm{mol} / \mathrm{cm}^{3}\right)$

$C_{\mathrm{CO}}^{*}$ : $\mathrm{CO}$ gas equilibrium concentration of reaction $\mathrm{FeO}+\mathrm{CO}=\mathrm{Fe}+\mathrm{CO}_{2}\left(\mathrm{~mol} / \mathrm{cm}^{3}\right)$

$\bar{d}$ : Mean diameter of particles $(\mathrm{cm})$

$D:$ Diffusivity $\left(\mathrm{cm}^{2} / \mathrm{sec}\right)$

$D_{\mathrm{CO}-\mathrm{CO}_{2}}$ : Coefficient of $\mathrm{CO}-\mathrm{CO}_{2}$ interdiffusivity $\left(\mathrm{cm}^{2} / \mathrm{sec}\right)$

$g$ : Gravity $\left(980 \mathrm{~cm} / \mathrm{sec}^{2}\right)$

$k_{c}$ : Rate constant of chemical reaction $(\mathrm{cm} / \mathrm{sec})$

$k_{g}$ : Mass transfer coefficient in gas film $(\mathrm{cm} / \mathrm{sec})$

$K$ : Rate constant of overall reaction $(\mathrm{cm} / \mathrm{sec})$

$L:$ Length of isothermal zone (cm)

$M$ : Molar weight (-)

$M_{\mathrm{CO}}, M_{\mathrm{CO}_{2}}$ : Molar weight of $\mathrm{CO}$ and $\mathrm{CO}_{2}(-)$

$\dot{n}_{c}$ : Chemical reaction rate $(\mathrm{mol} / \mathrm{sec})$

$\dot{n}_{g}:$ Mass transfer rate in gas film $(\mathrm{mol} / \mathrm{sec})$

$\dot{n}_{\text {overall }}$ : Overall reaction rate $(\mathrm{mol} / \mathrm{sec})$

$\mathrm{O}_{i}$ : Number of oxygen mole of specimen before reduction (mol)

$P: \quad$ Pressure (atm)

$Q:$ Flow rate of gas $\left(\mathrm{cm}^{3} / \mathrm{min}\right)$

$r_{0}$ : Radius of molten particles before reduction (cm)

$r_{p}:$ Radius of molten particle $(\mathrm{cm})$

$R:$ Degree of reduction (\%)

$R e:$ Reynolds number (-)

$S:$ Area of cross section of reactor tube $\left(\mathrm{cm}^{2}\right)$

Sc: Schmidt number (-)

$t$ : Residence time of particle (sec)

T: Temperature (K)

T. Fe (1): Content of total Fe of specimen before reduction $(\%)$

T. Fe (2): Content of total Fe of specimen after reduction (\%)

$U_{g}:$ Velocity of gas $(\mathrm{cm} / \mathrm{sec})$

$U_{p}$ : Velocity of particle $(\mathrm{cm} / \mathrm{sec})$

$U_{s}$ : Terminal velocity of particle $(\mathrm{cm} / \mathrm{sec})$

$\Delta G^{\circ}$ : Standard Gibbs energies of reaction (cal $/ \mathrm{mol}$ )

$\mu$ : Viscosity of gas $(\mathrm{g} / \mathrm{cm} \mathrm{sec})$

$\mu_{\mathrm{CO}}:$ Viscosity of CO gas $(\mathrm{g} / \mathrm{cm} \mathrm{sec})$

$\rho_{g}:$ Density of CO gas $\left(\mathrm{g} / \mathrm{cm}^{3}\right)$

$\rho_{p}:$ Density of particles $\left(\mathrm{g} / \mathrm{cm}^{3}\right)$

$\rho_{1}$ : Density of wustite $\left(\mathrm{mol} / \mathrm{cm}^{3}\right)$

$\rho_{2}:$ Density of iron $\left(\mathrm{mol} / \mathrm{cm}^{3}\right)$

$\sigma:$ Collision diameter (A)

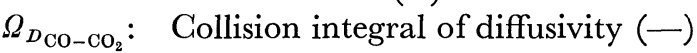

$\Omega \mu:$ Collision integral of viscosity $(-)$

\section{REFERENCES}

1) M. W. Davies, G.S.F. Hazeldean and P. N. Smith: Physical Chemistry of Process Metallurgy, The Richardson Conference, July, (1974), 95.

2) F. Fun: Met. Trans., 1 (1970), 2537.

3) M. Sugata, T. Sugiyama and S. Kondo: Tetsu-to-Hagané, 58 (1972), 1363.

4) K. Takahashi, M. Amatatsu and T. Sōma: Tetsu-toHagané, 61 (1975), 2525.

5) Y. Sasaki, Y. Okamoto and T. Sōma: Tetsu-to-Hagané, 64 (1978), 367.

6) P. Grieveson and E. T. Turkdogan: Trans. AIME, 230 (1964), 1609.

7) K. Kato, Y. Sasaki and T. Sōma: Trans. ISIJ, 17 (1977), 532.

8) J. O. Hirshfelder, G. F. Curtiss and R. B. Bird: Molecular Theory of Gases and Liquids, John Wiley \& Sons, New York, (1954).

9) T. Saito, M. Amatatsu and S. Watanabe: Bull. Research Inst. Mineral Dressing and Met., Tohoku Univ., 25 (1969), 67.

10) K. Mori and K. Suzuki: Tetsu-to-Hagané, 54 (1968), 1123.

11) F. D. Richardson and J.H.E. Jeffes: JISI, 160 (1948), 261.

12) W. E. Ranz and W. R. Marshall: Chem. Eng. Prog., 48 (1952), 141.

13) B. J. Miller: Rate Processes of Extractive Metallurgy, Plenum Press, New York, (1979), 222.

14) S. Taniguchi, A. Kikuchi and S. Maeda: Tetsu-to-Hagané, 62 (1976), 191. 